Received : 12.04.2019 \& Accepted : 22.05.2019 \& Published (online) : 26.06.2019

\title{
HFACS Analysis for Investigating Human Errors in Flight Training Accidents
}

\author{
Bilal KILIÇ* (iD
}

Faculty of Aviation and Aeronautical Sciences, Özyegin University, Istanbul, Turkey

\begin{abstract}
Training of pilots in civil aviation is the primary concern when dealing with accidents and incidents. There has been too little research into accidents during flight instruction. To advance the literature, the present study aims to analyze accidents during the instructional general aviation flights. This study examined investigation reports of 70 accidents involving instructional general aviation flights in the United States between 01.01.2018 and 12.12.2018. The accident data obtained from the National transportation safety board (NTSB) accident data system. The causal factors of those accidents were statistically analyzed and classified by using the Human Factors Analysis and Classification System (HFACS). To the best of our knowledge, this paper is the first ever report analyzing contributing factors of training flight accidents by the analytical framework HFACS. According to the analysis results, it was revealed that across all accidents mentioned above, skill-based errors were ranked as the primary contributing factors, followed by environmental factors, and decision errors. Results showed that the most common skill-based errors are student pilots' improper landing flare and failure to maintain directional control during landing and takeoff. The findings of this study provide intriguing insight that may be beneficial to people researching contributing factors of aviation accidents in academia and practice. Furthermore, the outcome of the current study may assist student pilots in completing safe flights.
\end{abstract}

Keywords: Pilot training, accident investigation, ab-initio pilots, human factors analysis and classification system (HFACS), general aviation

\section{Introduction}

Recent years have witnessed a growing interest in pilot training due to substantial growth in civil aviation and global pilot shortage $[1,2]$. In line with this unprecedented growth and demand for pilots, a great number of Approved training organizations (ATOs) and universities all around the world have launched flight training programs for ab-initio pilots over the past decade [3, 4]. For instance, there are

*Corresponding Author: Dr. Öğr. Üyesi Bilal KILIC bilal.kilic@ozyegin.edu.tr
199 approved flight training organizations registered at South African civil aviation authority [5], and 620 FAA-approved pilot schools (certified in accordance with Title 14, Code of Federal Regulations part 141) in the USA [6]. The operations of these flight schools and approved training organizations are conducted under the regulation of general aviation. General aviation

Citation: Kilic, B (2019). HFACS analysis for investigating human errors in instructional flights: Understanding the Human Factors Contribution to Flight Training Accidents. Journal of Aviation, 3 (1), 28-37 DOI: 10.30518/jav.553315 
includes flight activities not involving commercial air transportation, such as search and rescue services, agricultural application, emergency medical applications, and flight instruction [7].

Accidents in general aviation account for more than 90 percent of fatalities in civil aviation. Compared with commercial jet airplane operations(passenger and cargo flights) where accident rates have shown a significant decrease during the past two decades, accident rates in general aviation operations have remained stubbornly unchanged for the last twenty years $[8$, 9]. There are various contributing factors (e.g., human factors, meteorology, new training approaches, and new aircraft crashworthiness design, etc.) causing general aviation accidents which should be examined. Furthermore, the most common causality in general aviation accident has been found to be pilot error [10]. In our earlier work, it was demonstrated that ab-initio pilot training is of paramount importance concerning civil aviation safety [11]. With that in mind, for a better understanding of accidents in ab-initio pilot training flights, the aim of the present study is to analyze contributing factors to those accidents mentioned above.

\subsection{General Aviation}

General aviation (14 CFR Part 91) is basically all civilian non-scheduled flying including non-commercial business aviation, aerial work (i.e., agriculture, observation and patrol, photography, construction, and surveying), pleasure flying, and instructional flying [7, 12]. Flights performed by general aviation aircraft have demonstrated a substantial increase in the last three decades all around the world. Unfortunately, only a modest decrease has been witnessed in general aviation accidents and incidents parallel with the growth of the general aviation operations [8, 13, 14]. (Figure 1)

Despite the technological, educational and design efforts made by the authorities and organizations, accidents in civil aviation remains one of the most important and unsettled problems in aviation[15, 16].

\subsection{Instructional Flight and Human Factors}

Instructional flights are the essence of aviation. Namely, pilot training plays a critical role in preventing accidents and incidents in aviation [17]. Pilot-related causal factors remain stubbornly high in aviation accident despite the improved aircraft

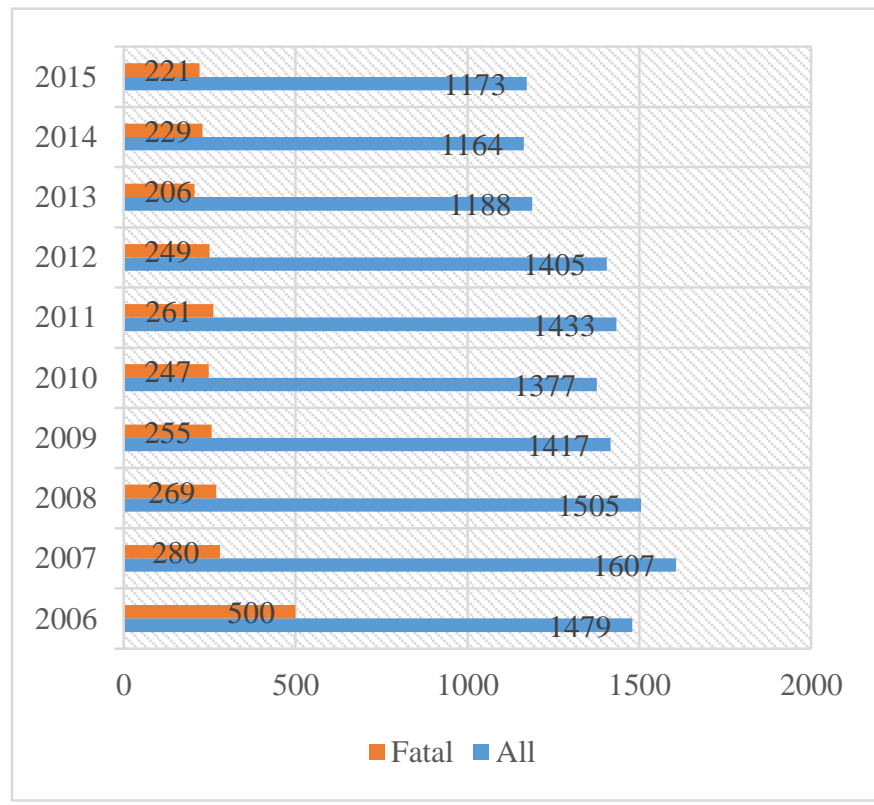

Figure 1. Overall general aviation accidents, 2006-2015

reliability and modern educational methods (e.g., evidence-based training, threat and error management, crew resource management training) [18-20].

Student pilots are prone to cause failures during early stages of training since they have relatively little experience (flying hours and knowledge) [21]. Another important threat to conducting safe operations in aviation is fatigue [22]. A training flight is not as long as an airline flight and student pilots are not exposed to the same challenges (e.g., extended wakefulness and circadian disruption) as airline pilots, even a shorter flight may cause fatigue due to high-workload (i.e., single-pilot operation) and stressful nature of the flight training [23]. Furthermore, they suffer from work-related stressors due to lack of knowledge and limited situational awareness [24]. Kharoufah et al. have reported that the most common contributing factor of aviation accidents is situational awareness [25]. Hence, situational awareness of student pilots plays an essential role in pilot training. ATOs and pilot training departments of universities should pay attention to this issue and launch novel courses 
involving ways to enhance situational awareness of ab-initio pilots and improve training, culture, and proficiency.

\subsection{Instructional Flights Accidents}

Flight training accidents are of paramount importance to any individuals and organizations in aviation. Over the past decade, 1676 instructional accidents resulting in injury or death have been reported in the USA (Table 1). Of the 1676 accidents, the type of aircraft was fixed-wing in 1419 of the accidents. Approximately 11 percent of those accidents were fatal. Based on the data obtained from NTSB, the number of instructional accidents has shown only a modest decrease over the past decade [26] (Figure-3). Multiple studies have consistently reported the importance and severity of instructional accidents [27-29]. These studies shed light on the causality of the flight training accidents and help the flight training industry to continue to get safer.

Table 1. Number of accidents and type of injuries occurred during the instructional flights between 2009 and 2019 in the USA [30].

\begin{tabular}{cccc}
\hline $\begin{array}{c}\text { Highest } \\
\text { Injury }\end{array}$ & $\begin{array}{c}\text { Fixed- } \\
\text { wing }\end{array}$ & Helicopter & Both \\
\hline Fatal & 166 & 19 & 185 \\
Minor & 156 & 56 & 212 \\
None & 1005 & 165 & 1170 \\
Serious & 90 & 17 & 107 \\
Unknown & 2 & 0 & 2 \\
Total & 1419 & 257 & 1676 \\
\hline
\end{tabular}

\subsection{Human Factor Analysis and Classification System (HFACS)}

HFACS is one of the most widely used comprehensive and reliable analytical frameworks to examine and classify causal factors of accidents and incidents in various industries such as medicine [31], construction [32], maritime [33], mining industry [34], oil and gas [35], railways [36] and aviation [11, 37-39] FAA also uses it for the investigation of causality of the accidents and incidents [40].

In the HFACS framework (Figure-2), there are four levels based on James Reason's 4 Levels of error causation [40, 41]. Level-1 represents "unsafe acts of the operators" and comprises of two subcategories: "errors" and "violations". The first subcategory "errors" includes three sub-groups: decision errors, skill-based errors, and perceptual errors. The second sub-category "violations" has two sub-headings. These are; routine violations and exceptional violations.

Level-2 "preconditions for unsafe acts" is composed of three sub-categories: "environmental factors," "preconditions of operators," and "personal factors." The first sub-category "environmental factors" is examined under two subheadings; technological environment and physical environment. The second sub-category "substandard condition of operators" is divided into three groups; "adverse mental state," "adverse physiological state," and "physical/mental limitations." The third sub-category of the Level-2 is composed of two sub-headings; "crew resource management (CRM)," and "personnel readiness."

Level-3 "unsafe supervision" of the HFACS framework represents errors and violations that arise from decisions made by management. There are three sub-categories in the Level-3; "inadequate supervision," "planned inappropriate operations," "failed to correct problem," and "supervisory violations."

Level-4 is the most underestimated category in the analysis of an occurrence. Any mistakes or inappropriate actions at this level directly affect lower levels. Namely, any improper conditions in the Level-4 result directly in unsafe supervision (Level-3) and the unsafe supervision gives rise to preconditions for unsafe acts. 

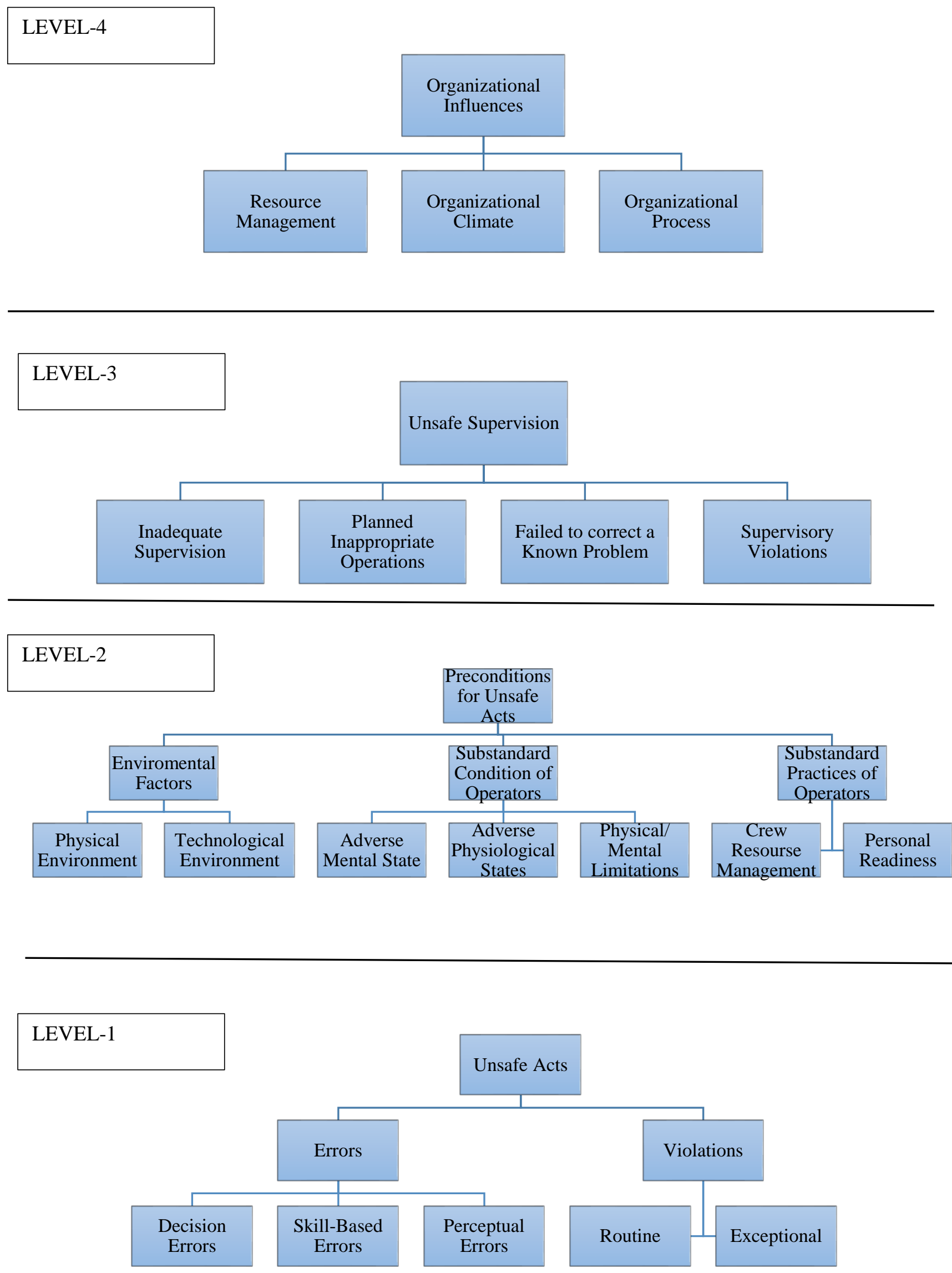

Figure 2. The HFACS framework 


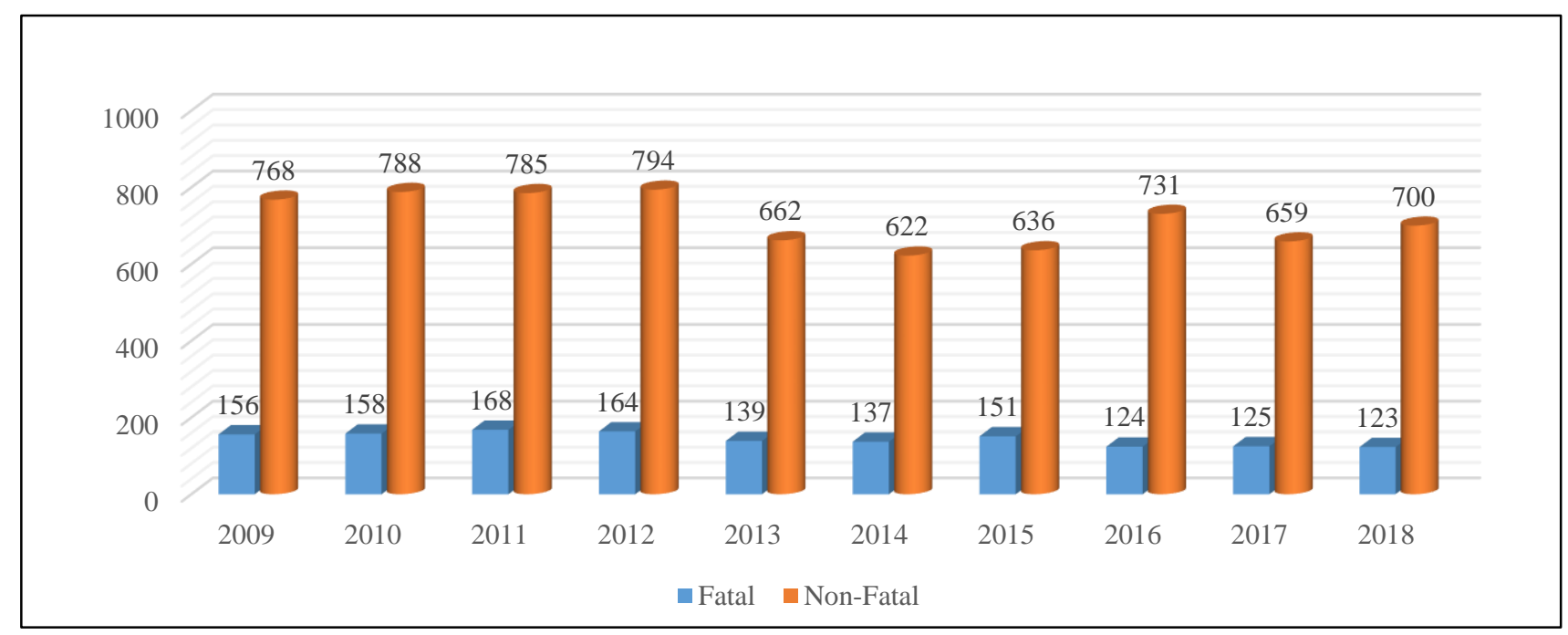

Figure 3. Instructional accidents, 2009-2018 (Fixed-Wing) [26]

Level-4 of the HFACS framework comprises of three sub-categories; "resource management," "organizational climate," and "organizational process."

In the analysis of an accident/incident, contributing factors are examined and assigned to one or more of the sub-categories. We previously reported a few studies to apply HFACS for the analysis of the contributing factors to airspace infringements (e.g., gross navigation errors during the transatlantic flights) [11, 42]

\section{Methodology}

The official report of 70 accidents from 01.01.2018 to 12.12.2018 in the USA were obtained by NTSB accident databases and examined [26]. The accidents were selected based on the following criteria;

- Type of occurrence: Accident

- Operation: Part91-General Aviation

- Purpose of flight: Instructional

- Aircraft Category: Airplane

- Report Status: Probable Causes

- Injury Severity: Fatal\&Non-fatal

2 categories were coded by code 0 (absence) and code 1 (presence). For the coding process, we have not created any new contributing factors. In other words, the contributing factors identified by NTSB were used. The analysis of the data after the coding process was carried out by using the excel spreadsheet.

\section{Results and Discussion}

\subsection{Data Analysis}

In the accidents coded, 171 category assignments were carried out to classify the contributing factors underlying the 70 accidents. The obtained statistics were analyzed and shown with graphics and tables. The presence of HFACS codes in 70 instructional flight accidents is demonstrated in Table 2.

\subsection{Discussion}

Detailed analysis of the contributing factors of 70 instructional flight accidents was conducted to illuminate the actual risks involved. The causal categories associated with each level of the HFACS framework will be discussed in this section.

From Table 2, it is observed that the most significant contributing factors were skill-based errors. The results are directly in line with previous findings. Wiegmann and Shappell have previously reported that skill-based errors were the primary contributing factors of accidents across all types of operations in the U.S. Air Force, U.S. commercial air carriers, and U.S. general aviation [43]. It is an undeniable fact that pilot training is the breeding ground for the entire aviation world. Therefore, flight instructors should pay attention to basic flying skills of ab-initio pilots and prevent a lack of skill or knowledge (i.e., crosswind takeoff and landing techniques) which keep them away from trouble. 
Table 2. The frequency and percentage of 70 accidents by HFACS categories

\begin{tabular}{|c|c|c|}
\hline $\begin{array}{l}\text { HFACS } \\
\text { Category }\end{array}$ & Frequency & $\begin{array}{c}\% \text { of all } \\
\text { accidents }\end{array}$ \\
\hline Decision Error (1) & 17 & 24,28 \\
\hline Skill-Based Error (1) & 56 & 80 \\
\hline Perceptual Errors (1) & 17 & 24,28 \\
\hline Routine Violations (1) & 12 & 17,14 \\
\hline Exceptional Violations (1) & 0 & 0 \\
\hline Physical Environment (2) & 41 & $\mathbf{5 8 , 5 7}$ \\
\hline $\begin{array}{l}\text { Technological } \\
\text { Environment (2) }\end{array}$ & 1 & 1,42 \\
\hline Adverse Mental State (2) & 20 & $\mathbf{2 8 , 5 7}$ \\
\hline $\begin{array}{l}\text { Adverse Physiological } \\
\text { State (2) }\end{array}$ & 0 & 0 \\
\hline $\begin{array}{l}\text { Physical/ } \\
\text { Mental Limitations (2) }\end{array}$ & 0 & 0 \\
\hline CRM (2) & 3 & 4,29 \\
\hline Personal Readiness (2) & 3 & 4,29 \\
\hline Inadequate Supervision (3) & 1 & 0,58 \\
\hline $\begin{array}{l}\text { Planned inappropriate } \\
\text { Operations (3) }\end{array}$ & 0 & 0 \\
\hline $\begin{array}{l}\text { Failed to correct a known } \\
\text { problem (3) }\end{array}$ & 0 & 0 \\
\hline Supervisory Violations (3) & 0 & 0 \\
\hline Resource Management (4) & 0 & 0 \\
\hline Organizational Climate (4) & 0 & 0 \\
\hline Organizational Process (4) & 0 & 0 \\
\hline Total & 171 & \\
\hline
\end{tabular}

The data also showed that decision errors were associated with one-quarter of the accidents. This is consistent with what has been found in the previous study [44]. Decision making is of paramount importance for safe operation in aviation because it has been determined that most of the accident occurred due to decision-making errors [45]. Therefore, innovative learning strategies, such as computer-assisted learning can be implemented into ab-initio flight training to develop decision-making skills amongst ab-initio pilots [46]. The pilot training program of aviation faculties and flying schools should implement innovative teaching approaches to develop human factor skills. Furthermore, human factors training shall be integrated into ab-initio flight training.

Wiegmann et al., have reported that only 5.7 percent of the general aviation accidents occurred due to perceptual errors. Contrary to the findings of Wiegmann et al., perceptual errors gave rise to 25 percent of the accidents within the present analysis. Most frequent perceptual errors for fatal and nonfatal accidents in general aviation were misperceptions in visual/aural indications and aircraft's speed, altitude and attitude [44]. Flight instructors should pay attention to the abovementioned perceptual errors. During the debriefing period of each flight, flight instructors should encourage student pilots to become actively involved in identifying their strengths and personal limitations. As a result, students might realize what they need do to improve their performance and, in turn, consciousness-raising among ab-inito pilots can be obtained.

A further novel finding is that physical environment (e.g., terrain, weather, altitude, heat, and lightning) is the second highest contributing factor associated with 70 flight training accidents that occurred in the United States between 01.01.2018 and 12.12.2018. This finding is consistent with those of Wiegmann's [47] findings which showed that 1020 commercial aviation accidents over a 13-year period occurred mostly due to environmental causal factors and flight crew related contributing factors(errors and violations). A significant number of environmental conditions (e.g., crosswind, gusty wind, wind shear, and thermal lift) were found to contribute to those accidents we examined. To eliminate causal factors classified under the heading physical environment, ab-initio pilots should be taught how to get and interpret weather-related information (e.g., actual weather reports and forecasts, aeronautical charts, sigmet charts, and snowtam). Since weather-related decision-making is of paramount importance for the preflight and inflight portion of a fight operation [48], students shall acquire a sound knowledge of meteorology. During the briefing session of an 
instructional flight, instructors should mention the importance of environmental conditions and their potential adverse effects on the flight.

The percentage of the causal factors associated with each level of the HFACS framework is shown in Figure 4. Upon closer examination of the data, it stands out that "preconditions for unsafe acts" appears to be prevalent (37\%). More than 60 percent of the accidents were associated with an unsafe act. We were surprised to find out that the final reports and probable cause reports of the instructional flight accidents do not contain any information about the organizational influences and a few accidents were associated with unsafe supervision.

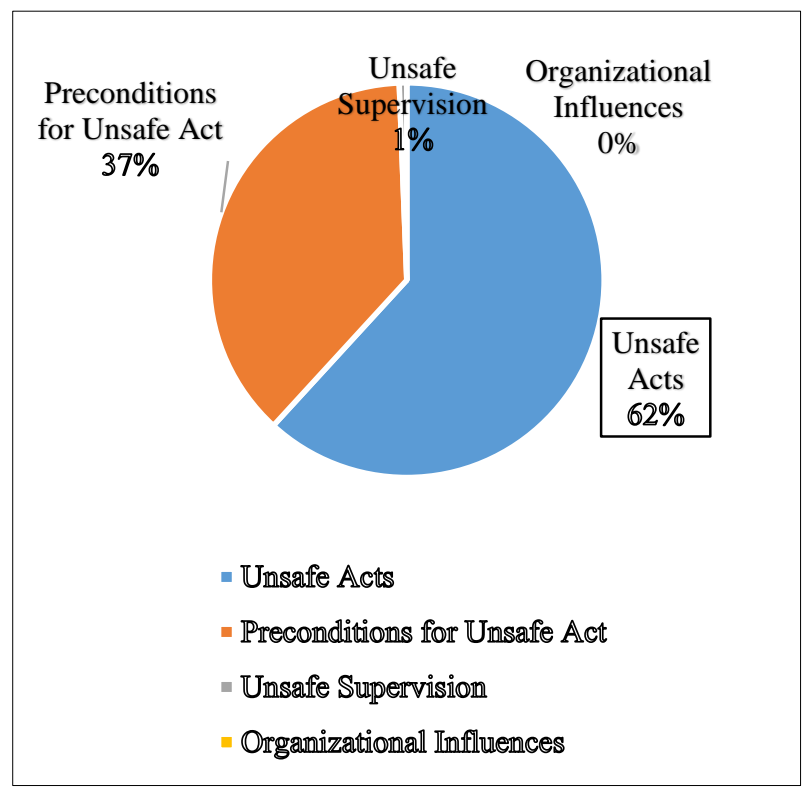

Figure 4. The percentage of causal factors under the four levels of HFACS framework.

It is a well-known fact that the take-off and landing are most critical phases of the flight for accidents/incidents in both commercial and general aviation. During instructional flights, especially solo flights, pilots become busier with many important tasks (e.g., ATC communication and controlling flight path in final approach and landing phases. In line with previous studies, we found that nearly 72 percent of all accidents (n:70) occurred in final approach and landing phase of the flight [39]. Figure 5 demonstrates that $11,43 \%$ of total accidents occurred in the taxi phase of the flight, 5,71 percent in the takeoff phase, 2,86 percent in the climb phase, 5,71 percent in landing rollout.

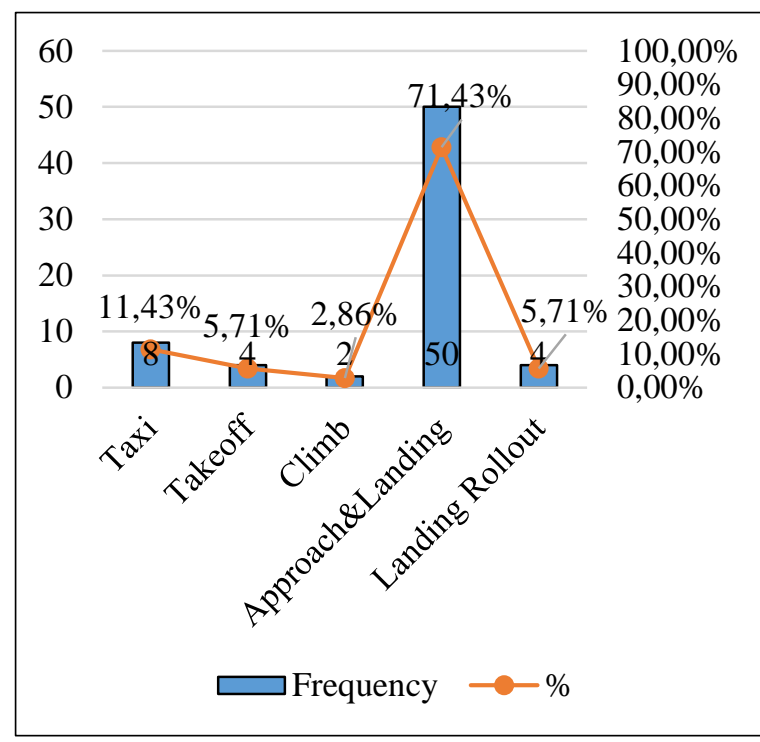

Figure 5. Instructional flight accidents -phase of flight

It has been found that nearly 36 percent of the accidents ( $\mathrm{N}: 25)$ happened during solo flights. More than 60 percent of the accidents $(\mathrm{N}: 45)$ occurred during training flights conducted with a qualified instructor pilot (Figure 6). These findings are very much in line with the review of Air Safety Institute 2014 [49]. From these results dual instruction carries a greater risk than solo student flights.

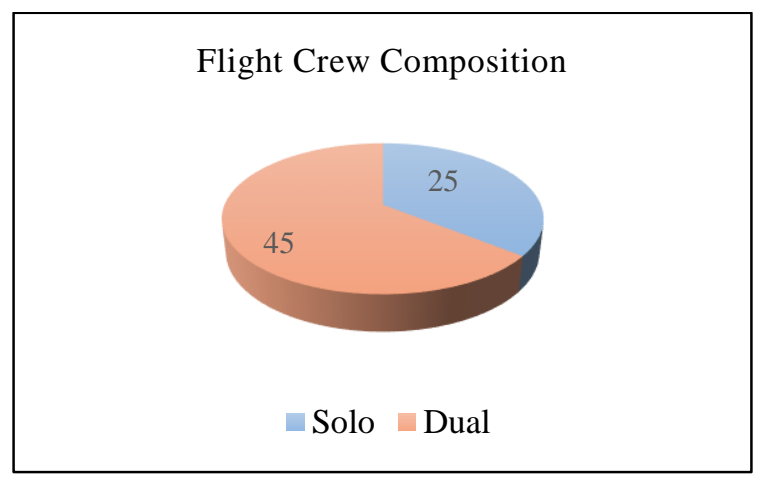

Figure 6. Flight crew composition of instructional flight accidents

Another important outcome of this study is that out of 70 accidents, only one accident happened due to fuel mismanagement. Moreover, no preaccident mechanical malfunction or failures with the training aircraft have been reported for those accidents which is in-line with the literature [49]. 


\section{Conclusion}

Finally, we were able to categorize the contributing human factors in 70 training flight accidents properly. To the best of our knowledge, this is the first study to examine the contributing factors of instructional flight accidents by using HFACS framework. It has been demonstrated that physical environment, decision errors, and skillbased errors are the most common causal factors.

Our findings can be exploited by ATOs and pilot training department of universities to train student pilots at prescribed international standards and to reduce the likelihood of human errors. Furthermore, organizations may enforce safety constraints for civil aviation by examining causal factors and their interrelationships.

One of the limitations of the study is to collect information about latent errors (Level-4 and Level3 of HFACS framework) from accident reports. Thus, we were not able to examine the relationship between higher levels (Level-4 and Level-3) and lower levels (Level-1 and Level-2) of the HFACS framework.

Another limitation of this study is the absence of cockpit voice recorder (CVR) and flight data recorder (FDR) onboard of general aviation aircraft which provide crucial information on man-machine interaction. As a result, a more generic, less-finegrained analysis of instructional flights accidents cannot be performed.

As a future study, the relationship between subcategories at four levels of the HFACS framework should be done to support the underpinning theory behind the most widely used analytical tool in aviation, HFACS. Future research studies should focus on elusive latent failures and investigations of the instructional flight accidents and should consider the likelihood of errors and violations made by the top-level organizations or the management of the flight training departments of universities and ATOs. Even though there are several limitations to this study that were already mentioned above, it provides a promising avenue for more future research.

\section{References}

[1] ATAG-Air Transprt Action Group, “Aviation Benefits Beyond Borders," 2018.

[2] BOEING, "Current market outlook 20172036," 2017.

[3] FlightschoolList.com, "Airplane Flight Schools from all over the world," https://www.flightschoollist.com/airplaneflight-schools/. [Accessed: 20-Mar-2019].

[4] FlightschoolList.com, "Aviation Collage and Universities from all over the world," https://www.flightschoollist.com/aviationcollege/. [Accessed: 20-Mar-2019].

[5] SACAA, "Approved Training Organizations-Pilot Training (South African Civil Aviation Authority)," http://www.caa.co.za/Aviation Personnel Standards/List of ATOs and AMTOs.pdf. [Accessed: 20-Mar-2019].

[6] FAA, "FAA-Pilot Schools," http://avinfo.faa.gov/PilotSchool.asp. [Accessed: 11-Apr-2019].

[7] ICAO, "ICAO-WORKING PAPERREVIEW OF THE CLASSIFICATION AND DEFINITIONS USED FOR CIVIL AVIATION," Montreal, 2009.

[8] D. D. Boyd, "A Review of General Aviation Safety (1984-2017)," Aerosp. Med. Hum. Perform., vol. 88, no. 7, pp. 657-664, 2017.

[9] BOEING, "Statistical Summary of Commercial Jet Airplane Accidents (Worldwide Operations 1959 - 2016)," 2017.

[10] Aviation Safety, "Problems with Flight Training," http://www.aviationsafetymagazine.com/air plane/Flight-Training-Mistakes.html. [Accessed: 11-Apr-2019].

[11] B. Kilic and S. Soran, "How Can an AbInitio Pilot Avert a Future Disaster: A Pedagogical Approach to Reduce The Likelihood of Future Failure," J. Aviat., vol. 3, no. 1, pp. 1-14, 2019.

[12] Electronic Code of Federal Regulations, "General Operating and Flight Rules," https://www.ecfr.gov/cgi-bin/textidx? node $=14: 2 \cdot 0 \cdot 1.3 .10$. [Accessed: 02Apr-2019].

[13] AOPA Air Safety Foundation, "State of General Aviation General,” 2019. 
[14] AOPA Air Safety Foundation, "JOSEPH T. NALL REPORT General Aviation Accidents in 2015," 2015.

[15] M. Aguiar, A. Stolzer, and D. D. Boyd, "Rates and causes of accidents for general aviation aircraft operating in a mountainous and high elevation terrain environment," Accid. Anal. Prev., vol. 107, no. March, pp. 195-201, 2017.

[16] D. D. Boyd, "General aviation accidents related to exceedance of airplane weight / center of gravity limits," Accid. Anal. Prev., vol. 91, pp. 19-23, 2016.

[17] Flight Global, "Pilot training is the key to preventing serious accidents," 2019. .

[18] Y. H. Chang, H. H. Yang, and Y. J. Hsiao, "Human risk factors associated with pilots in runway excursions," Accid. Anal. Prev., vol. 94, pp. 227-237, 2016.

[19] ICAO, "ICAO Manual Doc 9995-Manual of Evidence-based Training," 2013.

[20] M. J. W. Thomas, "ERROR MANAGEMENT TRAINING - Defining Best Practice," 2004.

[21] W. Li, "The Casual Factors of Aviation Accidents Related to Decision Errors in the Cockpit by System Approach," J. Aeronaut. Astronaut. Aviat., vol. 43, no. 3, pp. 159166, 2011.

[22] Z. Göker, "Fatigue in The Aviation: An Overview of The Measurements and Countermeasures," vol. 2, no. 2, pp. 185194, 2018.

[23] FAA, "Fatigue in Aviation," 2018.

[24] M. R. Endsley and D. J. Garland, "Pilot Situation Awareness Training in General Aviation," in Proceedings of the Human Factors and Ergonomics Society Annual Meeting, 2000, vol. 44, no. 11, pp. 357-360.

[25] H. Kharoufah, J. Murray, G. Baxter, and G. Wild, "A review of human factors causations in commercial air transport accidents and incidents: From to 2000-2016," Prog. Aerosp. Sci., vol. 99, pp. 1-13, 2018.

[26] NTSB-National Transportation Safety Board, "Aviation Accident Database \& Synopses,"

https://www.ntsb.gov/_layouts/ntsb.aviation /index.aspx. [Accessed: 30-Mar-2019].

[27] A. Walton, C. Baumann, and R. C. Geske,
"Fatal Flight Training Accident report 2000-2015," 2015.

[28] B. Siyuan, M. Guindani, and D. D. Boyd, "Causes of fatal accidents for instrumentcertified and non-certified private pilots," Accid. Anal. Prev., vol. 72, pp. 370-375, 2014.

[29] W. C. N. Taneja, "Weather related fatal general aviation accidents: Can spatial disorientation training be an effective intervention strategy?," Ind J Aerosp. Med, vol. 46, no. 2, pp. 59-64, 2002.

[30] AOPA Air Safety Foundation, "Accident Analysis-Accident Database," https://www.aopa.org/asf/ntsb/search_ntsb. cfm. [Accessed: 03-Apr-2019].

[31] T. Diller, G. Helmrich, S. Dunning, S. Cox, A. Buchanan, and S. Shappell, "The Human Factors Analysis Classification System (HFACS) Applied to Health Care," Am. J. Med. Qual., vol. 29, no. 3, pp. 181-190, 2014.

[32] N. Xia, P. X. W. Zou, X. Liu, X. Wang, and R. Zhu, "A hybrid BN-HFACS model for predicting safety performance in construction projects," Saf. Sci., vol. 101, no. September 2017, pp. 332-343, 2018.

[33] M. Celik and S. Cebi, "Analytical HFACS for investigating human errors in shipping accidents," Accid. Anal. Prev., vol. 41, no. 1, pp. 66-75, 2009.

[34] M. G. Lenné, P. M. Salmon, C. C. Liu, and M. Trotter, "A systems approach to accident causation in mining: An application of the HFACS method," Accid. Anal. Prev., vol. 48, pp. 111-117, 2012.

[35] A. L. Aas, "The Human Factors Assessment and Classification System (HFACS) for the Oil \&amp; Gas Industry," in International Petroleum Technology Conference, 2008, no. 4.

[36] Q. Zhan, W. Zheng, and B. Zhao, "A hybrid human and organizational analysis method for railway accidents based on HFACSRailway Accidents (HFACS-RAs)," Saf. Sci., vol. 91, pp. 232-250, 2017.

[37] W. C. Li, D. Harris, and C. S. Yu, "Routes to failure: Analysis of 41 civil aviation accidents from the Republic of China using the human factors analysis and classification system," Accid. Anal. Prev., vol. 40, no. 2, 
pp. 426-434, 2008.

[38] K. Dönmez and S. Uslu, "İnsan Faktörleri Analiz ve Sinıflandirma Sistemi'nin (HFACS) Literatürde Yaygın Kullanımının Değerlendirilmesi-Evaluation of the Widespread Use of Human Factors Analysis and Classification System ( HFACS) in Literature," J. Aviat., vol. 2, no. 2, pp. 156176, 2018.

[39] K. Donmez and S. Uslu, "THE RELATIONSHIP BETWEEN FLIGHT OPERATIONS AND ORGANIZATIONS IN AIRCRAFT ACCIDENTS; THE APPLICATION OF THE HUMAN FACTOR ANALYSIS AND CLASSIFICATION SYSTEM," Anadolu Univ. J. Sci. Technol. A-Applied Sci. Eng., vol. 19, pp. 316-333, 2018.

[40] S. Shappell and D. Wiegmann, "The Human Factors Analysis and Classification System - HFACS,” 2000.

[41] J. T. Reason, Human Error. Cambridge: Cambridge University Press, 1990.

[42] C. A. Havle and B. Kılıç, "A hybrid approach based on the fuzzy AHP and HFACS framework for identifying and analyzing gross navigation errors during transatlantic flights," J. Air Transp. Manag., vol. 76, pp. 21-30, 2019.

[43] S. Shappell and D. Wiegmann, "HFACS Analysis of Military and Civilian Aviation Accidents: A North American Comparison," in ISASI, 2004, pp. 1-8.

[44] S. Shappell, C. Detwiler, K. Holcomb, C. Hackworth, A. Boquet, and D. Wiegmann, "Human Error and Commercial Aviation Accidents : A Comprehensive, Fine- Office of Aerospace Medicine Human Error and Commercial Aviation Accidents: A Comprehensive , Fine-Grained Analysis Using HFACS Scott Shappell,” 2006.

[45] B. Strauch, "Decision Errors and Accidents : Applying Naturalistic Decision Making to Accident Investigations," J. Cogn. Eng. Decis. Mak., vol. 10, no. 3, pp. 281-290, 2016.

[46] D. O'Hare, Human Performance in General Aviation, 1st ed. London and Newyork: Routledge Taylor \& Francis Group, 1999.

[47] D. A. Wiegmann, A. Boquet, S. Shappell, K. Holcomb, C. Hackworth, and C. Detwiler,
"Human Error and Commercial Aviation Accidents: An Analysis Using the Human Factors Analysis and Classification System," Hum. Factors, vol. 49, no. 2, pp. 227-242, 2017.

[48] M. W. Wiggins, D. Azar, J. Hawken, T. Loveday, and D. Newman, "Cue-utilisation typologies and pilots, pre-flight and inflight weather," Saf. Sci., vol. 65, pp. 118124, 2014.

[49] AOPA Air Safety Institute, "ACCIDENTS DURING FLIGHT INSTRUCTION: A REVIEW,” 2014. 